\title{
Chapter 25 \\ Coastal Community Preferences of Gray, Green, and Hybrid Infrastructure Against Tsunamis: A Case Study of Japan
}

\author{
Yui Omori, Koichi Kuriyama, Takahiro Tsuge, Ayumi Onuma, \\ and Yasushi Shoji
}

\begin{abstract}
A decade has passed since the 2011 Great East Japan Earthquake and Tsunami struck. Despite increasing awareness that concrete-based coastal infrastructure, such as seawalls, is not sufficient to protect against unfathomable events, engineering structures still play a significant role in fortifying coastal communities. Meanwhile, purely nature-based approaches (i.e., coastal forests) also have limitations against cataclysmic waves, and there remain uncertainties regarding their ecosystem-based disaster risk reduction functions (Eco-DRR). In tackling these issues, hybrid infrastructure, which combines both gray and green components, has received growing interest. However, little research has been conducted to evaluate the economic values of coastal gray, green, and hybrid infrastructures under uncertainties in terms of people's preferences.

Therefore, in this study, we aimed to (1) quantify the economic value of coastal ecosystem services, including species richness, landscape, recreational services, and disaster risk reduction, under uncertainties through choice experiments; (2) clarify the differences in preferences for preparations against long-cycle tsunamis between those who reside in tsunami-prone areas and those who do not, using a conditional logit (CL) model; and (3) discuss the heterogeneities in coastal citizen perceptions by comparing the CL and mixed logit (ML) model. As a result, this study highlights the importance of considering the heterogeneity of preferences.
\end{abstract}

\footnotetext{
Y. Omori $\cdot$ K. Kuriyama $(\bowtie)$

Division of Natural Resource Economics, Graduate School of Agriculture, Kyoto University,

Kyoto, Japan

e-mail: omori.yui.27x@ st.kyoto-u.ac.jp; kkuri@kais.kyoto-u.ac.jp

T. Tsuge

Sophia University Graduate School of Global Environmental Studies, Tokyo, Japan
}

A. Onuma

Keio University, Graduate School of Economics, Tokyo, Japan

Y. Shoji

Research Faculty of Agriculture, Hokkaido University, Hokkaido, Japan

(C) The Author(s) 2022

F. Nakamura (ed.), Green Infrastructure and Climate Change Adaptation,

Ecological Research Monographs, https://doi.org/10.1007/978-981-16-6791-6_25 
Furthermore, our respondents in the tsunami-prone group (TPG) valued the coastal defense function offered by gray more highly than the non-TPG, demonstrating an especially large gap regarding seawalls against short-cycle tsunamis (willingnessto-pay (WTP) values of 11,233 JPY and 5958 JPY, respectively). However, there was no significance for coastal forests in the TPG, reflecting the importance of disaster prevention function offered by gray infrastructure. In addition, the hybrid landscape (seawalls + coastal forests) received higher positive responses, $71.1 \%$ with WTP of 8245 JPY, than the gray landscape (seawalls only) with WTP of -3358 JPY, as estimated by the ML model. These contradictions and heterogeneities in people's preferences may foreshadow the difficulties of applying hybrid approaches; hence developing synthesized both stated preference and other revealed preference methods is indispensable for providing strategic design of gray-green combined coastal defense and bolstering coastal realignment.

Keywords Seawalls - Coastal forests - Hybrid infrastructure · Eco-DRR · Choice experiments

\subsection{Introduction}

A decade has passed since the 2011 Great East Japan Earthquake and Tsunami occurred, which caused severe damages to both human life and socioeconomic properties both on the coast and in the hinterlands. After these events, artificial coastal defenses, including 10-m-high seawalls, have been constructed on some coastlines in Japan. The reliance on traditional defense methods continues despite increasing awareness that gray-based coastal infrastructure alone does not offer sufficient tsunami protection. Then, discussions regarding the reconstruction of higher and wider seawalls prompted coastal residents to rethink their coastal infrastructure because they both benefit from the ocean but also bear the brunt of natural hazards, such as tsunamis, windstorms, storm surges, and typhoons.

Over centuries, coastal design and planning have become an engineering discipline, initially for economic development, such as harbors and ports. Their spatial advantages have led to the development of human settlements, as coastlines provide resources, trading, and job opportunities, thus the global population benefits directly and indirectly from marine ecosystems (McGranahan et al. 2007). Moreover, population growth in coastal zones is accelerating, and more than half of coastal countries have $80 \%-100 \%$ of their population within $100 \mathrm{~km}$ of their coastlines (Martínez et al. 2007). Similarly, the intensity and frequency of natural hazards are increasing, implying that coastal zones are becoming more vulnerable. Thus, minimizing the impact of natural disasters is increasingly imperative. In particular, seawalls are considered to be the last line of defense and essential for maintaining residential livelihood (Reeve et al. 2018), as they have important roles in stabilizing the shoreline and protecting the coastal communities of Japan.

In parallel, Pinus thunbergii (black pine trees) has been traditionally afforested along coasts in Japan as a nature-based disaster mitigation method to collect 
blown sand, mitigate wind speeds, and protect agricultural products and residential buildings. Moreover, coastal forests can be planted to attenuate wave velocity and stop drifts, thereby providing evacuation time when tsunamis occur (Harada and Imamura 2005). However, purely green measures have limitations against catastrophic events. Broadly, artificial coastal barriers (termed gray infrastructure, built infrastructure or hardened structures, encompassing seawalls, levees, culverts, bulkheads) ensure greater protection during extreme weather events than their nature-based counterparts, such as mangroves, coastal forests, dunes, and salt marshes, unless the intensities of natural hazards go beyond the infrastructure's capacity (Onuma and Tsuge 2018). Conversely, coastal armoring can exert negative or unexpected influences on coastal habitats and prevent them from restoring after disturbances (Borsje et al. 2011). Furthermore, the high cost of construction and maintenance poses a financial burden on municipality budgets. To overcome these issues, green infrastructure has been given increasing interest and is recognized as a nature-based approach that can serve disaster mitigation. However, the performance of ecosystem-based disaster risk reduction (Eco-DRR) varies because of coastal morphology and land use configuration (i.e., topography, soil conditions, and vegetation) (Irtem et al. 2009). Furthermore, Gedan et al. (2011) stated that unfathomable events, such as large tsunami waves and storm surges, can overwhelm the attenuation effects provided by vegetation and emphasized the necessity of combining man-made structures with ecological means of coastal protection. As such, hybrid infrastructure, which combines gray and green components, has also received growing interest. Sutton-Grier et al. (2015) summarized the characteristics of coastal gray, green, and hybrid infrastructure, evaluating their strengths and weaknesses. Tanaka (2012) investigated the effectiveness and limitations of coastal pine forests against large tsunami and concluded that their ability to attenuate waves is not better than that of seawalls, which does not necessarily mean their effect is negligible when a large tsunami overtops coastal armoring. In addition, it emphasized that other functions, such as trapping debris, provided by coastal forests should be considered, and gray-green integrated approaches should be applied to future coastal designs. Hence, the hybrid approach of seawalls and coastal forests that has long been utilized in some coastal regions in Japan may be a solution to the current reliance on gray-based coastal defense and the ambiguous effects of green infrastructure on coastal protection (Table 25.1). However, because of the multiple types of gray and green integrations (TCHGG 2018), there is a lack of economic analysis considering hybrid infrastructure that integrates seawalls and coastal forests. Furthermore, the uncertainties of disaster risk reduction (DRR) function provided by green infrastructure (Eco-DRR) hinder policymakers from performing cost-benefit analyses as it is difficult to understand how gray and green combined infrastructure can reduce hazard risks. (Hereafter, we use the term "DRR," which is the abbreviation of disaster risk reduction provided by either gray or green, but again, especially DRR function offered by green is termed Eco-DRR.) This financial challenge has an ongoing issue for green infrastructure (Sutton-Grier et al. 2015), which has also led to limited implementation and data regarding hybrid infrastructure as well. 
Table 25.1 Coastal gray and green infrastructure strengths and weaknesses

\begin{tabular}{|c|c|c|}
\hline Infrastructure & Strengths & Weaknesses \\
\hline \multirow[t]{7}{*}{ Gray (seawalls) } & Greater level of protection & Coastal habitat loss \\
\hline & $\begin{array}{l}\text { - Alleviates speed of waves, } \\
\text { tsunamis }\end{array}$ & $\begin{array}{l}\text { - Has negative effects on other } \\
\text { ecosystem services that coasts } \\
\text { and surrounding areas, such as } \\
\text { beaches, provide }\end{array}$ \\
\hline & - Prevents erosion & $\begin{array}{l}\text { Lack of capability and high } \\
\text { maintenance cost }\end{array}$ \\
\hline & $\begin{array}{l}\text { - Withstands storm events soon } \\
\text { after seawalls are built and } \\
\text { performs stable protection for } \\
\text { two to three decades }\end{array}$ & $\begin{array}{l}\text { - Does not adapt to unforeseen } \\
\text { events (e.g., tsunamis, sea-level } \\
\text { rise) }\end{array}$ \\
\hline & $\begin{array}{l}\text { Greater understanding of } \\
\text { techniques and effects }\end{array}$ & $\begin{array}{l}\text { - Weakens the effects (built-in } \\
\text { lifetime) }\end{array}$ \\
\hline & $\begin{array}{l}\text { - Can perform to cost-benefit } \\
\text { analysis }\end{array}$ & $\begin{array}{l}\text { Lack of ocean and community } \\
\text { bond }\end{array}$ \\
\hline & $\begin{array}{l}\text { Significant engineering } \\
\text { expertise }\end{array}$ & $\begin{array}{l}\text { - Leads to safety } \\
\text { misunderstandings and disaster } \\
\text { risks }\end{array}$ \\
\hline \multirow[t]{8}{*}{ Green (coastal forests) } & Many co-benefits & Ambiguous effects \\
\hline & - Coastal protection & $\begin{array}{l}\text { - Limited understanding } \\
\text { regarding protection levels } \\
\text { because of topography, } \\
\text { vegetation, seasons, and soils }\end{array}$ \\
\hline & - Recreational use & Time for mature forests \\
\hline & $\begin{array}{l}\text { - Coastal habitats with many } \\
\text { species }\end{array}$ & $\begin{array}{l}\text { - Requires approximately } \\
20 \text { years to mature for sufficient } \\
\text { protection }\end{array}$ \\
\hline & Lower cost & Pine wilt disease \\
\hline & Adaptation to unexpected events & $\begin{array}{l}\text { - Damaged by diseases and } \\
\text { pests }\end{array}$ \\
\hline & $\begin{array}{l}\text { - Can keep pace with climate } \\
\text { change, sea-level rise }\end{array}$ & $\begin{array}{l}\text { Other societal disadvantages } \\
\text { (crime, dumping) }\end{array}$ \\
\hline & & $\begin{array}{l}\text { - Requires appropriate } \\
\text { maintenance }\end{array}$ \\
\hline \multirow[t]{4}{*}{$\begin{array}{l}\text { Hybrid (gray }+ \text { green: } \\
\text { seawalls }+ \text { forests) }\end{array}$} & $\begin{array}{l}\text { Greater protection with other } \\
\text { co-benefits }\end{array}$ & Little data and limited expertise \\
\hline & $\begin{array}{l}\text { - May require less space than } \\
\text { natural approaches alone }\end{array}$ & $\begin{array}{l}\text { - Requires more research } \\
\text { regarding potential effects }\end{array}$ \\
\hline & $\begin{array}{l}\text { Innovative coastal design and } \\
\text { planning }\end{array}$ & $\begin{array}{l}\text { - May require more space to } \\
\text { introduce both systems }\end{array}$ \\
\hline & $\begin{array}{l}\text { - Compatible with resilience } \\
\text { and authentic value }\end{array}$ & \\
\hline
\end{tabular}

Sources: Based on Sutton-Grier et al. (2015) and Harada and Imamura (2005), edited by the authors 
From an economic perspective, Costanza et al. (2008) evaluated the value of coastal wetlands for ecosystem protection against hurricanes in the United States and estimated the potential storm protection to be $\$ 23.2$ billion annually using a regression model. Barbier et al. (2011) evaluated the coastal ecosystem services (ESSs) in different natural environments, including coral reefs, seagrasses, salt marshes, mangroves, sand beaches, and dunes. However, these estimations of nonmarket values do not necessarily consider the trade-offs between ESSs in different coastal planning scenarios. Additionally, information regarding the potential values of coastal forests, especially Pinus thunbergii, is lacking. Thus, it is crucial to quantify the monetary values of ecosystem functions provided by concrete structures and natural measures. As there is a significant reliance on concrete structures, such as seawalls, and the uncertainties of DRR functions offered by coastal forests are still unclear, we considered seawalls as coastal gray infrastructure and coastal forests as green infrastructure (Fig. 25.1) in order to (1) evaluate the economic value of coastal ESSs, including species richness, landscape, recreational services, and DRR under uncertainties, (2) describe the preferences of coastal citizens regarding preparations against long-cycle tsunamis using economic models, and (3) discuss better combinations of gray and green infrastructure. In this project, we did not just aim at giving a monetary value of coastal ecosystem services but rather focused on how much coastal people understand the hazard risk and acknowledge the importance of coastal ecosystems; therefore, this study

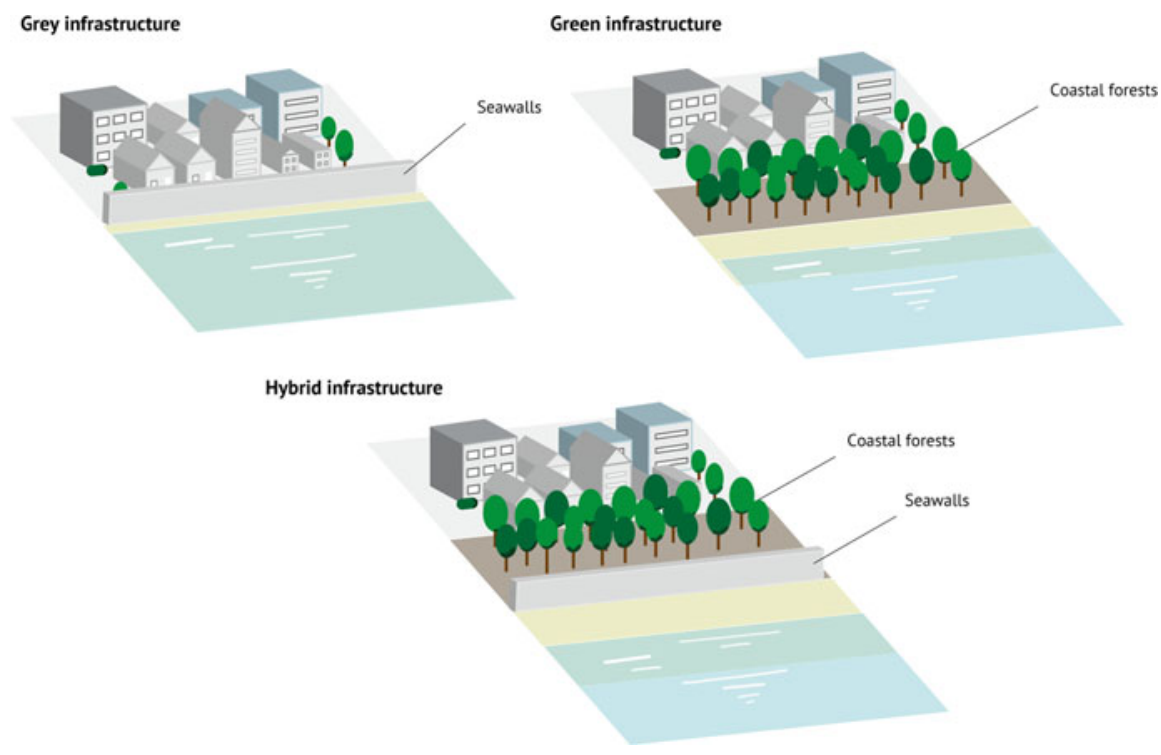

Fig. 25.1 Example of gray, green, and hybrid approaches in Japan's coastal zone. Source: Based on Sutton-Grier et al. (2015), edited by the authors 
identifies the reasons for which it remains difficult to build a consensus between municipalities and locals and promote hybrid approaches.

\subsection{Survey Design}

\subsubsection{Data Collection}

In this project, an online survey intended for people in their 20s to 60s in Japan was administered by Nikkei Research Inc. between March 6 and March 10, 2020. The subjects were randomly selected, and 955 responses were obtained. These data are summarized in Table 25.2. Note that the distances listed in Table 25.2 were calculated with open-source Geographic Information System QGIS 3.10 using

Table 25.2 Data collection

\begin{tabular}{|c|c|c|c|c|c|c|c|c|}
\hline \multicolumn{2}{|l|}{ Gender } & \multicolumn{3}{|c|}{ Distance (from the coastline: $\mathrm{km}$ ) } & \multicolumn{4}{|c|}{ Frequency of coastal use } \\
\hline Female & 466 & $(48.8 \%)$ & $<5$ & 295 & $(30.9 \%)$ & Almost every day & 12 & $(1.3 \%)$ \\
\hline Male & 487 & $(51 \%)$ & $5-10$ & 146 & $(15.3 \%)$ & 3-5 times/week & 4 & $(0.4 \%)$ \\
\hline \multirow[t]{2}{*}{ Others } & 2 & $(0.2 \%)$ & $10-15$ & 129 & $(13.5 \%)$ & 1-2 times/week & 13 & $(1.4 \%)$ \\
\hline & & & $15-20$ & 79 & $(8.3 \%)$ & 1-2 times/month & 61 & $(6.4 \%)$ \\
\hline \multicolumn{3}{|l|}{ Age } & $20-30$ & 80 & $(8.4 \%)$ & 1-2 times/year & 116 & $(12.1 \%)$ \\
\hline $20 \mathrm{~s}$ & 153 & $(16 \%)$ & $30-40$ & 51 & $(5.3 \%)$ & Vacation use & 112 & $(11.7 \%)$ \\
\hline $30 \mathrm{~s}$ & 176 & $(18.4 \%)$ & $40-50$ & 36 & $(3.8 \%)$ & Seldom & 345 & $(36.1 \%)$ \\
\hline $40 \mathrm{~s}$ & 242 & $(25.3 \%)$ & $>50$ & 45 & $(4.7 \%)$ & None & 278 & $(29.1 \%)$ \\
\hline $50 \mathrm{~s}$ & 181 & $(19 \%)$ & Missing data & 94 & $(9.8 \%)$ & Others & 14 & $(1.5 \%)$ \\
\hline \multirow[t]{2}{*}{$60 \mathrm{~s}$} & 203 & $(21.3 \%)$ & Minimum value & 0.1 & & & & \\
\hline & & & Maximum value & 102.7 & & & & \\
\hline \multicolumn{3}{|c|}{ Income (million JPY) } & \multicolumn{3}{|l|}{ Occupation } & & & \\
\hline$<2$ & 101 & $(10.6 \%)$ & Office workers & 429 & $(44.9 \%)$ & & & \\
\hline $2-4$ & 212 & $(22.2 \%)$ & Officials & 33 & $(3.5 \%)$ & & & \\
\hline $4-6$ & 218 & $(22.8 \%)$ & Association staff & 22 & $(2.3 \%)$ & & & \\
\hline $6-8$ & 163 & $(17.1 \%)$ & Self-employed & 73 & $(7.6 \%)$ & & & \\
\hline $8-10$ & 115 & $(12 \%)$ & Housekeepers & 140 & $(14.7 \%)$ & & & \\
\hline $10-12$ & 54 & $(5.7 \%)$ & Part-time jobs & 141 & $(14.8 \%)$ & & & \\
\hline $12-14$ & 29 & $(3 \%)$ & Retired & 50 & $(5.2 \%)$ & & & \\
\hline $14-16$ & 22 & $(2.3 \%)$ & No job & 29 & $(3 \%)$ & & & \\
\hline $16-18$ & 13 & $(1.4 \%)$ & Students & 20 & $(2.1 \%)$ & & & \\
\hline $18-20$ & 7 & $(0.7 \%)$ & Others & 18 & $(1.9 \%)$ & & & \\
\hline $20-22$ & 10 & $(1 \%)$ & & & & & & \\
\hline$>22$ & 8 & $(0.8 \%)$ & & & & & & \\
\hline $\begin{array}{l}\text { Missing } \\
\text { data }\end{array}$ & 3 & $(0.3 \%)$ & & & & & & \\
\hline
\end{tabular}


postal codes. Furthermore, answering postal codes was optional, and responders can type "9999999" or "0000000" in the questionnaires if they did not wish to provide.

\subsubsection{Experimental Design}

\subsubsection{Review of Economic Evaluation}

To evaluate nonmarket values, such as coastal ESSs, we employed choice experiments. The economic analysis of ESSs is essential for municipalities to conduct cost-benefit analyses for coastal planning. There are several methods to estimate the nonmarket values of coastal ESSs, including travel cost or hedonic methods, which are known as revealed preference. However, these methods are not applicable to coastal ESSs' evaluations because of their far-reaching direct and indirect effects (Börger et al. 2014). Thus, in this study, we applied a conjoint analysis, which is a stated-preference method that enables researchers to understand individual respondents' statements of ESSs and determine their preferences. For instance, Garber-Yonts et al. (2004) used choice experiments to estimate people's willingness to pay (WTP) by changing the levels of biodiversity conservation under different conservation programs in the Oregon Coast. However, the public perceptions of ESSs' benefits that both gray and green infrastructure offer, such as DRR function, richness, recreation, and landscape, are not well understood. To date, choice experiments have been conducted to investigate the preference of coastal citizens regarding seawalls and coastal habitat conservation (Imamura et al. 2016). Based on this, our choice experiments addressed citizen preferences by adding the DRR function attributes offered by either gray or green (or both) approaches. On the other hand, another challenge is that the estimates by stated-preference can be relatively stable over short periods of time, and the results for longer periods are likely to be unstable because of the environmental changes projected for 50-100 years into the future (Börger et al. 2014). Thus, we also included some future settings that coastal infrastructure might be presented with by changing different frequencies of tsunamis. Therefore, we are able to address these issues and reveal the changes in coastal citizens' preference in various scales of tsunamis, and we explain the details of how these settings are generated in the following section.

\subsubsection{Choice Experiments}

A conjoint analysis using choice experiments provides concrete ecological information on a variety of coastal settings and evaluates trade-offs by jointly considering a number of important attributes for different hypothetical situations. It is therefore a useful tool for evaluating people's perceptions of ESSs (Louviere 1988; Louviere et al. 2000). However, it requires careful descriptions of ESSs in the survey design in order to ensure the validity of the ecological data. In this sense, we considered four 
coastal settings, including the status quo with the six attributes (Fig. 25.2): additional seawall height, coastal forest width, landscape, biodiversity, recreation, and annual tax, owing to ensuring that each attribute could be adequately understood without causing confusion (Bateman et al. 2002) (Table 25.3). The choice experiment was repeated eight times for each respondent, during which the levels of attributes changed. It is noteworthy that the additional seawall height and coastal forest width are associated with gray and green components, respectively, enabling the evaluation of DRR functions. The detailed explanations of the attributes and levels are provided in Sect. 25.2.3.

\begin{tabular}{|c|c|c|c|}
\cline { 2 - 4 } \multicolumn{1}{c|}{} & Option 1 & Option 2 & Option 3 \\
\hline Additional seawall height & $\begin{array}{c}\text { the preparation for } \\
\text { one-in-100 year } \\
\text { probability tsunami }\end{array}$ & $\begin{array}{c}\text { storm surge } \\
\text { (not well preparation } \\
\text { for tsunami) }\end{array}$ & $\begin{array}{c}\text { the preparation for } \\
\text { one-in-10 year } \\
\text { probability tsunami }\end{array}$ \\
\hline Forest width & $0 \mathrm{~m}$ & $500 \mathrm{~m}$ & $300 \mathrm{~m}$ \\
\hline Landscape & seawall & coastal forest & both \\
\hline Recreation & No recreational services & Camping \& Walking & $\begin{array}{c}\text { Camping, Walking \& } \\
\text { Fishing }\end{array}$ \\
\hline Bird species & 3 kinds of birds & 10 kinds of birds & 20 kinds of birds \\
\hline Annual cost (JPY) & 30,000 & 3,000 & 10,000 \\
\hline Most preferable & $\downarrow$ & $\downarrow$ & 0 \\
\hline
\end{tabular}

Fig. 25.2 Example of question

Table 25.3 Attributes and levels of coastal settings

\begin{tabular}{l|l}
\hline Attributes & Levels \\
\hline Additional seawalls height (security) & \pm 0 (for typhoons and storm surges)/ \\
\hline & $+1 \mathrm{~m}-+2 \mathrm{~m}(1$-in-10 year tsunamis)/ \\
\hline & $+2 \mathrm{~m}-+5 \mathrm{~m}(1$-in-30 year tsunamis)/ \\
\hline Forest width & + over $5 \mathrm{~m}(1$-in-100 year tsunami) \\
\hline Landscape & $0 / 100 \mathrm{~m} / 200 \mathrm{~m} / 300 \mathrm{~m} / 500 \mathrm{~m}$ \\
\hline Coastal recreation & Coastal forest only/seawall only/both \\
\hline Coastal biodiversity (birds species) & $\begin{array}{l}\text { Walking only/camping and walking/fishing only/ } \\
\text { camping, walking and fishing/nothing }\end{array}$ \\
\hline Annual tax (JPY) & $3 / 10 / 20$ kinds of birds \\
\hline
\end{tabular}




\subsubsection{Attributes and Levels}

\subsubsection{Additional Seawall Height}

Following the 2011 earthquakes and tsunamis, the MILT (2012) established new tsunami disaster risk management, in which tsunamis are classified into two different levels: Level 1 (L1) tsunamis, which have return periods ranging from approximately several decades to 100 years, and relatively low tsunami inundation depths; and Level 2 (L2) tsunamis, which are likely to occur for longer return periods, such as a few hundred to a few thousand years, and cause widespread damage to both the coast and hinterlands. This Japanese tsunami hazard management strategy further stipulated that the height of a coastal embankment should be designed in preparation of L1 tsunamis, whereas coastal structures are designed in preparation for L2 tsunamis in order to assure more time for evacuation. Then, seawall heights rely on prefectural decisions and computer simulations, causing some seawalls to be higher than $10 \mathrm{~m}$ in some coastlines. In our study, coastal gray infrastructure was categorized into four settings (Fig. 25.3), and then we assumed that the seawall with $2 \mathrm{~m}$ in height and $2000 \mathrm{~m}$ in total length has already existed (Fig. 25.4). First, as

(a) Present (protection against storm surges)

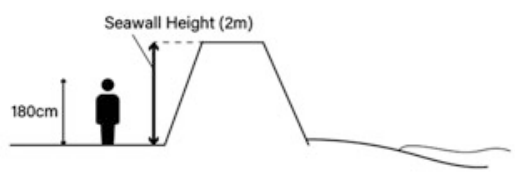

(b) Additional seawall height: $+1 \mathrm{~m} \sim$ less than $2 \mathrm{~m}$ (protection against one-in-10 year probability tsunamis)

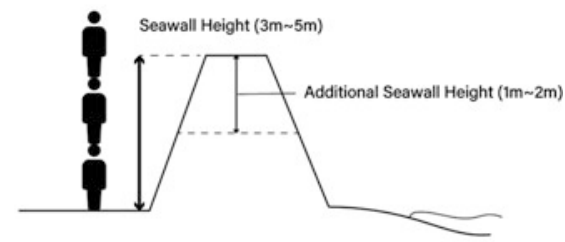

(d) Additional seawall height: + more than $5 \mathrm{~m}$ (protection against one-in-100 year probability tsunamis)

(c) Additional seawall height: $+2 \mathrm{~m} \sim$ less than $5 \mathrm{~m}$ (protection against one-in-30 year probability tsunamis)

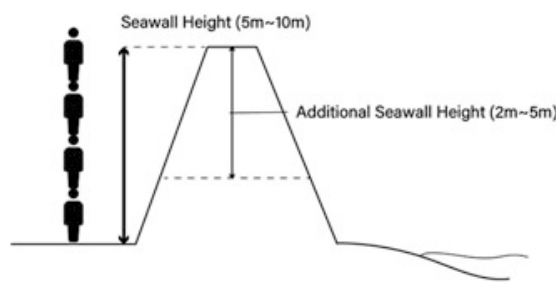

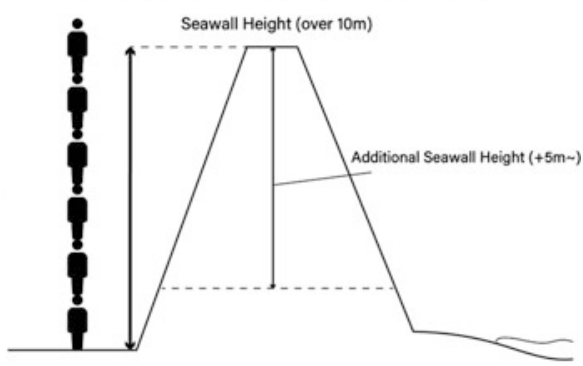

Fig. 25.3 Seawall settings. (a) Present situation (storm surge, not well prepared for tsunami); (b) $+1 \mathrm{~m}$-less than $2 \mathrm{~m}$ (the preparation for one-in-10 year probability tsunami), total seawall height: 3-5 m; (c) $+2 \mathrm{~m}$-less than $5 \mathrm{~m}$ (the preparation for a one-in-30 year probability tsunami), total seawall height: 5-10 $\mathrm{m}$; (d) + more than $5 \mathrm{~m}$ (the preparation for one-in-100 year probability tsunami), total seawall height: more than $10 \mathrm{~m}$. Note: The material that was used in our questionnaires is not permitted to use for commercial uses, so we here display the similar image above 


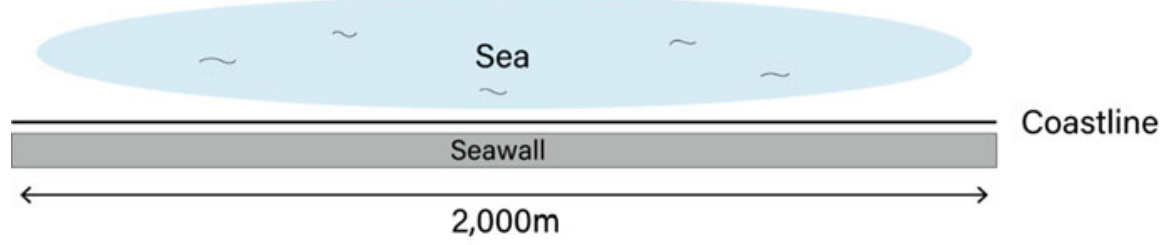

Hinterland

Fig. 25.4 The prerequisite of coastal land use. Note: Edited by the authors

shown in Fig. 25.3a (top left), there are no changes in a seawall with a height of approximately $2 \mathrm{~m}$ that already exists, providing effective protection from typhoons and storm surges. Second, as shown in Fig. 25.3b (top right), the additional height ranged 1-2 $\mathrm{m}$ will be constructed on the existing seawall in order to withstand a tsunami occurrence once a decade. Third, as shown in Fig. 25.3c (bottom left), a $2-5 \mathrm{~m}$ high seawall will be added to protect against 30 -year probability tsunamis. Finally, a seawall that is over $10 \mathrm{~m}$ high will be built to protect against unexpected tsunamis (Fig. 25.3d). To increase responders' comprehension, various tsunami frequencies were assumed, and a total seawall height does not mean the height from the Tokyo Peil (T.P.). The Japanese datum of leveling is commonly used to express a seawall height.

\subsubsection{Forest Width}

Coastal forests, in which Pinus thunbergii is predominant, span the interface of beaches and terrestrial environments and are mainly observed on the main island of Japan. In other types of coastal forests, mangrove forests exhibit significant wave attenuation (Bao 2011) and play important roles in DRR, providing habitats for coastal creatures (Barbier et al. 2011; Morris et al. 2018). Although the effects of coastal forests on tsunami mitigation are not well established, Harada and Imamura (2005) examined the effect of coastal forests and observed a reduction in tsunami inundation depth and hydraulic energy behind the forests with increasing forest width, which denotes the cross-shore distance (Fig. 25.5). On the other hand, Tanaka (2012) investigated the tsunami-affected regions of the 2011 earthquakes and tsunamis and found that the forest width that can mitigate tsunamis is at least $200 \mathrm{~m}$. This evidence was then applied to the government disaster management guidelines (MILT 2012). Specifically, if respondents selected coastal forests less than $200 \mathrm{~m}$ in width, they may prioritize protection from annual hazards such as wind storms rather than unexpected tsunami and wave attenuation, and if they select wider coastal forests, they desire a stronger protection level in both predicted 
(i) Coastal green infrastructure

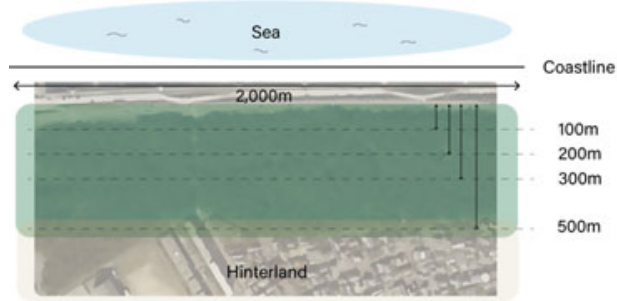

(ii) Coastal grey and green infrastructure

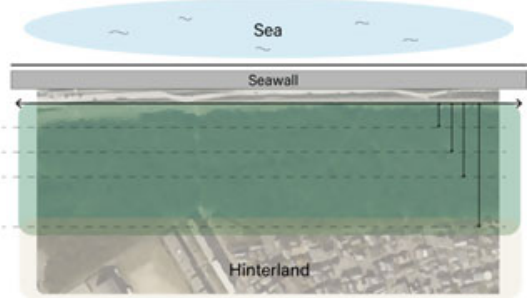

Fig. 25.5 Coastal forest scale. Source: Geospatial Information Authority of Japan, edited by the authors

and unpredicted natural disasters. Before beginning the choice experiment, we explained the positive and negative aspects concerning Eco-DRR, including that it has limitations and uncertainties in coastal protection (Onuma and Tsuge 2018). Then, we assume that coastal forests are afforested behind seawalls if they have already been constructed.

\subsubsection{Landscape}

Owing to increasing uncertainties in the face of multiple stressors, such as storm surges, typhoons, and coastal design for preparing against natural hazards, unforeseen events and several future scenarios must be considered. In this regard, coastal landscapes, also called "seascapes," which are associated with land use planning adjacent to the coastline and ocean, that integrate existing structures and natural approaches are gaining increasing attention. As coastal zones provide significant economic, transport, residential, and recreational functions, all of which have foundations in physical characteristics, they should have appealing landscapes, natural resources, and terrestrial biodiversity (European Commission 2000). PerkolFinkel et al. (2018) used ecologically sensitive designs and concrete technologies to minimize harmful impacts on marine flora and fauna. Concomitant to the growing threats of coastal hazards (Temmerman et al. 2013), anthropogenic changes in tourism and the development of residential districts are accelerating in coastal regions (Martínez et al. 2007). Subsequently, ecological engineering, which is relatively new discipline that combines engineering and ecology, has emerged to address these concerns (Chapman and Underwood 2011), and many studies regarding gray to green regime shifts and gray and green combined approach (hybrid) are available (Andersen et al. 2009; Cheong et al. 2013; Morris et al. 2018; Schoonees et al. 2019; Cooper et al. 2020), thereby augmenting coastal landscape architecture (Bergen et al. 2001; Pioch et al. 2018). Although interdisciplinary gray and green designs have been developed, there is limited information on how people value gray, green, and hybrid landscapes. Hence, to quantify gray and green coastal landscape from an economic point of view, our study placed landscape attributes 
(a) Seawall
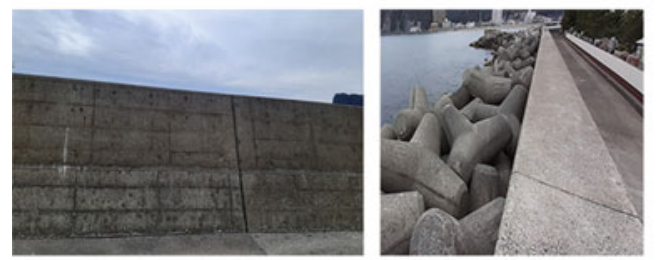

(b) Coastal Forest
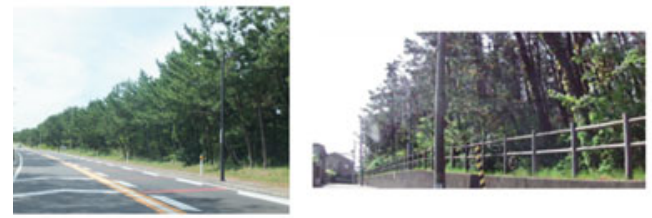

(c) Seawall \& Coastal Forest

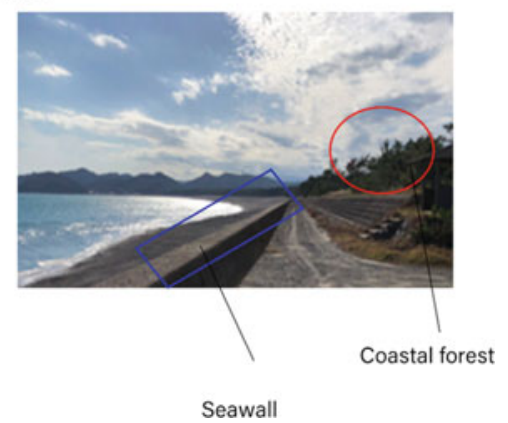

Fig. 25.6 Landscape photographs (a: gray, b: green, and c: gray + green). (a) Seawall. (b) Coastal forest. (c) Seawall and coastal forest. Source: The photo (c) was taken by researcher groups at Tokushima University

into choice experiments to explain the values of gray (seawalls), green (coastal forests), and gray + green (seawalls + coastal forests) landscapes. In addition, three photographs were provided during the choice experiment (Fig. 25.6).

\subsubsection{Recreation}

Recreation is an important ecosystem function and is a key element for evaluating estuarine and coastal ESSs (Barbier et al. 2011). Brenner et al. (2010) assessed the nonmonetary value of ecosystem functions provided by a coastal zone in Spain. They stressed the higher aesthetic and recreation values that contributed to the total coastal ecosystems. In previous studies, the direct uses of recreational benefits have been calculated via travel cost (Blackwell 2007; Ghermandi et al. 2009; Prayaga 2017). However, the indirect monetary value of recreational services is still not estimated, and the comprehensive understanding of recreational services offered by coastal pine forests is limited. Thus, our study classified coastal recreation into five cases: (a) a promenade provided for walking along coastlines, (b) fishing is permitted, (c) a promenade for walking and a space for camping near the ocean, (d) all three aforementioned activities are available, and (e) no recreation (Fig. 25.7).

\subsubsection{Bird Species}

Most marine flora and fauna reside in coastal areas; however, anthropogenic changes to coastlines are responsible for the loss of coastal habitats and associated ESSs 
(a) Walking

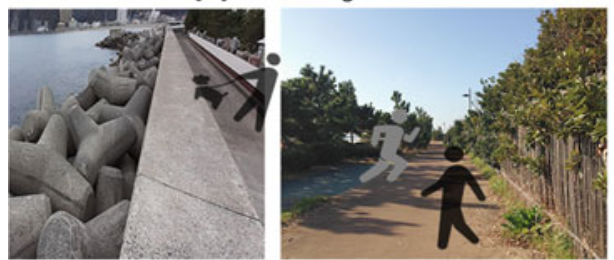

(c) Walking and Camping

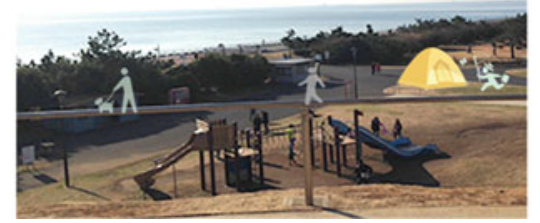

(b) Fishing

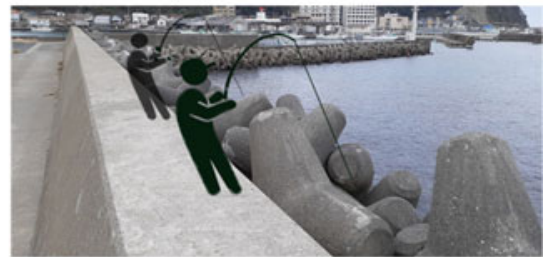

(d) Walking, Fishing and Camping

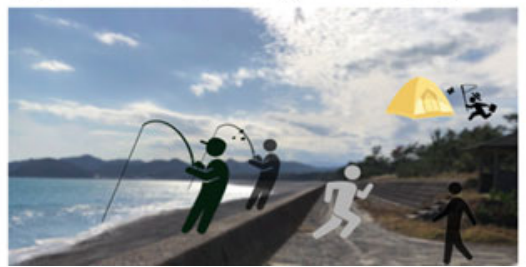

Fig. 25.7 Coastal recreation opportunities. (a) Walking. (b) Fishing. (c) Walking and camping. (d) Walking, fishing and camping. Note: As the material used in our questionnaires is not permitted for commercial use, we displayed a similar image above. The photos were provided only recreational activities are available for responders' understanding, but no recreation was reflected on the choice experiment (Fig. 25.2)

(Spalding et al. 2007). By accounting for the current ecosystems' values from human dimensions, some species are deemed more important than others. That is to say that the loss of some species at the peak of a food chain might have a very different effect than the loss of less charismatic species further down, which might support an entire ecosystem, called as a "keystone species" (Helm and Hepburn 2012). Thus, evaluating the monetary values of biodiversity is complex and difficult as it requires careful consideration from the perspectives of both human beings and animal conservation. Looking at the onshore environment, Sekercioglu (2006) stressed the ESSs provided by birds and avian ecological functions, such as predation, transportation, and excretion, which play significant roles in seed dispersal, pollination, controlling prey species populations, scavenging, and nutrient cycles. Canterbury et al. (2000) depicted the bird community as a useful tool for monitoring forest conditions. Thus, we regarded birds as keystone species in coastal zones using a scale of 3 to 20 kinds of birds, in accordance with Takagawa et al. (2011), who provided avian data in Japan. The small number of bird species indicated that Columba livia, Larus crassirostris, and Corvus (Corvus macrorhynchos or Corvus corone), which are generally seen in Japan, can be observed while a wide range of avian species is described as raptors and includes Pandion haliaetus and Accipiter gentilis, which are associated with higher consumers. These values are based on the annual number of average coastal birds to reduce migratory bird seasonal fluctuations. 


\subsubsection{Profile Design}

To describe efficient settings in the choice experiments, we applied a D-efficiency for optimal profile design using Ngene (ChoiceMetrics 2018), which is a common and comprehensive tool utilized in economic analyses. Unlike an orthogonal design that is statistically uncorrelated in attributes, D-efficiency can consider the interattribute correlation and allow analysts to exclude "insignificant" alternatives and to place more weight on practical situations (Hensher et al. 2005).

\subsection{Econometric Models}

\subsubsection{Conditional Logit and Mixed Logit Models}

Discrete choice models are derived based on utility maximization, in which the decision-maker selects an alternative that offers the greatest utility. Let $U_{n i}$ denote the utility that respondent $n$ obtains from alternative $i$ in choice set $C_{n}$ as follows:

$$
U_{n i}=V_{n i}+\varepsilon_{n i},
$$

where $V_{n i}$ is a deterministic component and $\varepsilon_{n i}$ is a random component, which are both assumed to be known to the individual, but unknown to the analyst. The probability that respondent $n$ will choose $i$ from alternative $j$ in choice set $C$ is the probability that $U_{n i}$ is larger than $U_{n j}$ as follows:

$$
\operatorname{Pr}(i)=\operatorname{Pr}\left[U_{i}>U_{j}\right]=\operatorname{Pr}\left[V_{i}-V_{j}>\varepsilon_{j}-\varepsilon_{i}\right] \forall j \neq i, \forall j \in C,
$$

where the index $n$ is omitted for simplification. Note that $U_{n i}$ depends on parameters that are unknown to the researcher and $\varepsilon_{n i}$ is the unobservable portion that respondent $n$ chooses alternative $i$.

This probability is a cumulative distribution as follows:

$$
\operatorname{Pr}_{i}=\operatorname{Pr}\left(\varepsilon_{j}-\varepsilon_{i}<V_{i}-V_{j} \forall j \neq i\right)=\int I\left(\varepsilon_{j}-\varepsilon_{i}<V_{i}-V_{j} \forall j \neq i\right) f(\varepsilon) d \varepsilon,
$$

where $I(\bullet)$ is an indicator function. Random utility models are obtained from different density specifications, which are then described as follows:

$$
U_{n i}=\beta^{\prime} x_{n i}+\varepsilon_{n i}
$$


When the utility is linear in $\beta$ and $x_{n i}$ is a vector of explanatory variables that are observed by the analysts and encompass the alternative attributes in a choice task, then $V_{n i}(\beta)=\beta^{\prime} x_{n i}$.

The distribution of the random component $\left(\varepsilon_{i}\right)$ is assumed to be a type I extreme value, and the probability that responder $n$ chooses alternative $i$ can be described in the conditional logit (CL) model as follows (McFadden 1974):

$$
P_{n i}=\frac{\exp \left(\beta^{\prime} x_{n i}\right)}{\sum_{j=1}^{J} \exp \left(\beta^{\prime} x_{n j}\right)}
$$

where the preference parameter is assumed to be constant for all respondents (Train 2009). When assuming the heterogeneity of preferences that vary across individuals, mixed logit (ML) probabilities are the integrals of standard logit probabilities over density parameters in the following equation:

$$
P_{n i}=\int L_{n i}(\beta) f(\beta \mid \theta) d \beta,
$$

where $L_{n i}(\beta)$ is the logit probability evaluated at $\beta$ and $f(\beta \mid \theta)$ is a density function, in which $\theta$ refers to the distribution. Thus, the ML probability takes the following form:

$$
P_{n i}=\int\left(\frac{e^{\beta^{\prime} x_{n i}}}{\sum_{j} e^{\beta^{\prime} x_{n j}}}\right) f(\beta) d \beta .
$$

ML is a mixture of logit functions that evaluate different's with $f(\beta)$ as the mixing distribution, wherein the utility (Eq. 25.4) takes a coefficient form (Train 2009), in which each of the coefficients is given an independent normal distribution with an estimated mean and standard deviation.

\subsubsection{Estimation}

The log likelihood for the model is described as follows:

$$
\operatorname{LL}(\theta)=\sum_{n} \ln P_{n i}(\theta) .
$$

Then, Eq. (25.8) is approximated by simulating for any given $\theta$, in which the simulated log likelihood is determined by maximizing $\operatorname{LL}(\theta)$; thus, Eq. (25.8) can be rewritten as follows:

$$
\operatorname{SLL}(\theta)=\sum_{n=1}^{N} \sum_{j}^{J} d_{n j} \ln \frac{1}{R} \sum_{r=1}^{R} L_{n i}\left(\beta^{r}\right),
$$

where $R$ is the number of draws and $d_{n j}=1$ if responder $n$ chooses $j$ plan and $d_{n j}=0$ if they do not. In the context of discrete choice models, Train (2009) explained 
the superior coverage of Halton draws and its effectiveness, as compared with a random draw, stating that 100 Halton draws improve model accuracy. Thus, this study utilized the maximum simulated likelihood with 100 Halton draws applying to the ML model.

\subsubsection{Versus ML Model}

Next, we compared CL model with ML model of coastal residents' choices of coastal infrastructure. The limitation of the CL is that it assumes the same parameters for all responders. Thus, a CL facilitates interpretation when assuming that the same categories of responders have the same preferences. Therefore, we divided the data into two categories: a tsunami-prone group for the respondents that reside in the area where it is likely to be inundated by tsunamis (TPG) and others, using ArcGIS 10.3.1 and a tsunami inundation map is provided by Ministry of Land, Infrastructure, and Transport. Consequently, we obtained 105 TPG samples, which accounted for $11 \%$ of all responses. Meanwhile, the ML model enables us to consider the heterogeneities and elucidate the distribution of preferences.

\subsubsection{WTP}

WTP measures are useful for interpreting change in a given attribute and are employed for several reasons. Given the limited budgets in municipalities and the pressure of hydro-meteorological events (i.e., floods and windstorms), WTP can illustrate how much people value goods, properties, and services. Accordingly, our choice experiments assume that a respondent will pay an annual tax to improve the level of a given attribute when they understand the needs or the desirability of coastal designs. WTP is calculated as follows:

$$
\mathrm{WTP}_{k}=-\frac{\beta_{k}}{\beta_{\mathrm{tax}}}
$$

where $\beta_{k}$ is the parameter of attribute $k$ and $\beta_{\operatorname{tax}}$ is the parameter of the tax.

\subsection{Results}

Table 25.4 lists the variables and definitions used in our analysis. Besides, Table 25.5 summarizes the estimation results of the CL model for the TPG and the others. As previously mentioned, the CL model assumes the same parameters for all respondents. In TPG, the attributes, except for forest, bird, and recreation, were found to be statistically significant at the $1 \%$ or $5 \%$ level. In contrast, for the non- 
Table 25.4 Variables and definitions

\begin{tabular}{l|l}
\hline Variables & Definitions \\
\hline asc & $\begin{array}{l}\text { A dummy variable representing respondents' answers for alternative 4 (choose } \\
\text { nothing) }\end{array}$ \\
\hline sea10 & $\begin{array}{l}\text { Whether alternatives including one-in-10 year probability tsunamis were chosen } \\
(0-1 \text { dummy) }\end{array}$ \\
\hline sea30 & $\begin{array}{l}\text { Whether alternatives including one-in-30 year probability tsunamis were chosen } \\
(0-1 \text { dummy) }\end{array}$ \\
\hline sea100 & $\begin{array}{l}\text { Whether alternatives including one-in-100 year probability tsunamis were } \\
\text { chosen }(0-1 \text { dummy) }\end{array}$ \\
\hline forest & Coastal forest width \\
\hline bird & Species richness (the number of avian species) \\
\hline landsc_sea & $\begin{array}{l}\text { Whether alternatives including gray (seawalls) landscape were chosen }(0-1 \\
\text { dummy) }\end{array}$ \\
\hline landsc_both & $\begin{array}{l}\text { Whether alternatives including hybrid (seawalls }+ \text { coastal forests) landscape } \\
\text { were chosen }(0-1 \text { dummy) }\end{array}$ \\
\hline rec_walk & Whether alternatives including walking were chosen $(0-1$ dummy) \\
\hline rec_fish & Whether alternatives including fishing were chosen $(0-1$ dummy) \\
\hline rec_camp & Whether alternatives including camping were chosen $(0-1$ dummy) \\
\hline
\end{tabular}

Table 25.5 Estimation results

\begin{tabular}{l|l|l|l|l|l|l}
\hline & \multicolumn{3}{l}{ Tsunami-prone sample } & Others & \\
\cline { 2 - 7 } & Coef. & $z$ & $p$-value & Coef. & $z$ & $p$-value \\
\hline sea10 & 0.4557 & 2.93 & 0.00 & 0.2230 & 4.1 & 0.00 \\
\hline sea30 & 0.5126 & 2.96 & 0.00 & 0.4292 & 7.14 & 0.00 \\
\hline sea100 & 0.4642 & 4.22 & 0.00 & 0.4134 & 10.7 & 0.00 \\
\hline forest & 0.0020 & 0.08 & 0.94 & 0.0268 & 3.13 & 0.00 \\
\hline bird & -0.0061 & -0.94 & 0.35 & -0.0054 & -2.35 & 0.02 \\
\hline landsc_sea & -0.2207 & -2.02 & 0.04 & -0.1137 & -2.97 & 0.00 \\
\hline landsc_both & 0.2273 & 2.2 & 0.03 & 0.2456 & 6.67 & 0.00 \\
\hline rec_walk & 0.0706 & 0.53 & 0.60 & 0.0249 & 0.53 & 0.59 \\
\hline rec_fish & 0.1350 & 1.35 & 0.18 & 0.0003 & 0.01 & 0.99 \\
\hline rec_camp & -0.0145 & -0.11 & 0.91 & 0.0114 & 0.24 & 0.81 \\
\hline price & -0.0406 & -5.42 & 0.00 & -0.0374 & -14.45 & 0.00 \\
\hline asc & -0.5868 & -3.13 & 0.00 & -0.4123 & -6.3 & 0.00 \\
\hline Number of obs & 3360 & & & 27,200 & & \\
\hline Log likelihood & -1099.51 & & & -9031.88 & & \\
\hline Pseudo R2 & 0.056 & & & 0.042 & & \\
\hline
\end{tabular}

TPG group, which has less likelihood that their residences will suffer from tsunami inundation, most of the attributes were statistically significant, with the exception of recreation. Furthermore, Table 25.6 demonstrates the WTP results for both groups based on the findings listed in Table 25.5. Regarding seawalls, one remarkable finding was that the TPG had a higher WTP for short-cycle tsunamis than the non-TPG (11,233 JPY and 5958 JPY, respectively). Moreover, the highest WTP 
Table 25.6

Willingness-to-pay (WTP)

estimation (JPY)

\begin{tabular}{l|r|r|c}
\hline & \multicolumn{1}{l|}{ TPG } & \multicolumn{1}{c|}{ Other } & TPG-other \\
\hline sea10 & 11,233 & 5958 & 5275 \\
\hline sea30 & 12,635 & 11,470 & 1165 \\
\hline sea100 & 11,441 & 11,046 & 395 \\
\hline forest & 48 & 716 & -668 \\
\hline bird & -152 & -146 & -6 \\
\hline landsc_sea & -5439 & -3038 & -2401 \\
\hline landsc_both & 5602 & 6564 & -962 \\
\hline rec_walk & 1741 & 665 & 1076 \\
\hline rec_fish & 3328 & 8 & 3320 \\
\hline rec_camp & -358 & 305 & -663
\end{tabular}

values were estimated for the mid-term tsunami in both groups, reaching 12,635 JPY and 11,470 JPY for the TPG and others, respectively. In coastal forests, the WTP values/100 m was 716 JPY for the non-TPG, whereas it had no significance in the TPG. As for the number of bird species, both groups showed negative perceptions ( -152 JPY in TPG and -146 JPY in others). Likewise, we observed negative WTP values for the gray-based coastal landscape in both groups. Simultaneously, the gray + green landscape had higher WTP values, at 5602 JPY for the TPG and 6564 JPY for the others.

Next, to consider preference heterogeneity, we applied all the data into both the CL and ML models for comparison (Table 25.7). Again, CL assumes the same parameters for all respondents, while ML assumes that individuals have different preferences. Thus, the former tends to overestimate the WTP. The normally distributed coefficients, estimated means, and standard deviations listed in Table 25.8 reflect the distribution of preferences. For example, the distribution of the seawalls with a 30-year-tsunami coefficient had an estimated mean of 0.44 and an estimated standard deviation of 1.19 , such that $68.7 \%$ of the distribution was above zero and $31.3 \%$ was below. This indicates that two-thirds of the respondents view a seawall for a mid-term tsunami as a positive and prefer it, whereas one-third do not prefer it. Similarly, compared with seawalls for three different frequencies, seawalls for long-term tsunamis had an estimated mean of 0.12 and an estimated standard deviation of 1.88 , implying $53.2 \%$ positive and $46.8 \%$ negative attitudes. A similar trend was observed for the short-term tsunamis with an estimated mean of 0.17 and a standard deviation of 1.19 , implying $57.2 \%$ of respondents supported it and $42.8 \%$ did not. Regarding coastal forests, the results revealed that $60.3 \%$ of respondents accepted coastal defense by green infrastructure, whereas $39.7 \%$ did not. On the one hand, for landscape, gray + green (seawalls + coastal forests) obtained high positive responses $(71.1 \%$ in positive and $28.9 \%$ in negative), while $61.3 \%$ of respondents showed negative perceptions toward gray landscape (seawalls only). Looking at bird species, $64.9 \%$ of responders had negative preferences regarding an increased number of birds. Conversely, regarding recreation, no significant results were obtained. Nevertheless, in the CL model, the recreation parameters were positive for various activities; however, the mean values of these ones in the ML model were 
Table 25.7 Conditional logit (CL) and mixed logit (ML) model results

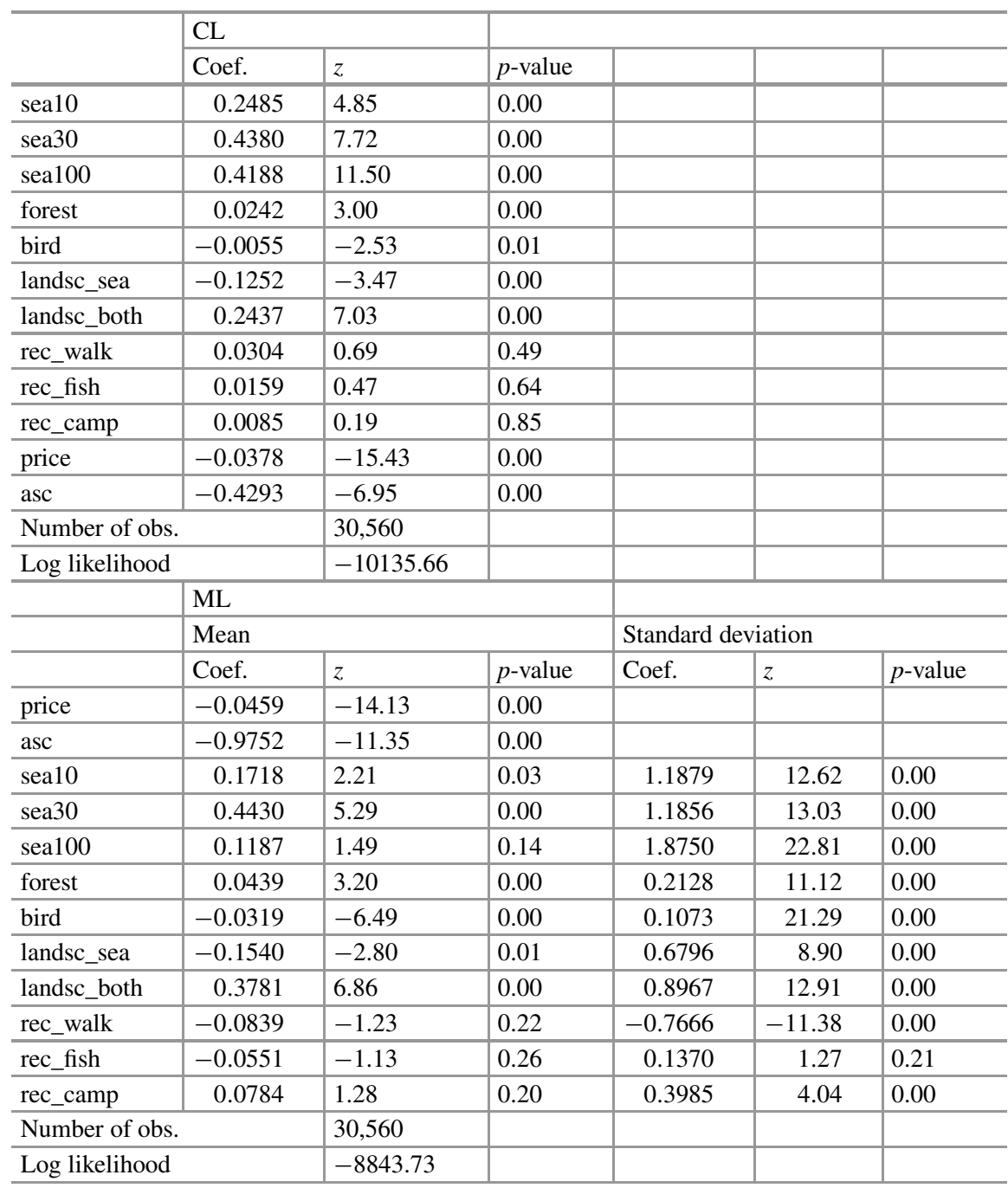

contrasting, with the exception of camping. It is worth noting that the ML model can reflect the distribution of respondents' preferences (Fig. 25.8). Finally, the WTP results in each model showed significant differences regarding seawall variables. In particular, in seawalls for long-cycle tsunamis, the WTP calculated by the CL model was 8504 JPY higher than that in the ML model. However, it is not always the case that the CL model overestimates all attributes except coastal forests and landscape (gray + green) variables. Overall, we found that the CL model's overestimation is significant in gray infrastructure and that it is not easy to apply the stated preference method for long periods of time. Moreover, the average WTP/100 m of coastal 
Table 25.8 Willingness-to-pay (JPY)

\begin{tabular}{l|c|l|c}
\hline & Conditional logit (CL) & Mixed logit (ML) & CL-ML \\
\hline sea10 & 6582 & 3747 & 2834 \\
\hline sea30 & 11,602 & 9662 & 1941 \\
\hline sea100 & 11,094 & 2590 & 8504 \\
\hline forest & 642 & 957 & -316 \\
\hline bird & -146 & -696 & 550 \\
\hline landsc_sea & -3318 & -3358 & 40 \\
\hline landsc_both & 6455 & 8245 & -1791 \\
\hline rec_walk & 806 & -1830 & 2636 \\
\hline rec_fish & 420 & -1202 & 1622 \\
\hline rec_camp & 226 & 1710 & -1484 \\
\hline
\end{tabular}

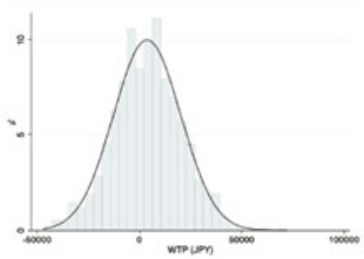

(a) sea 10

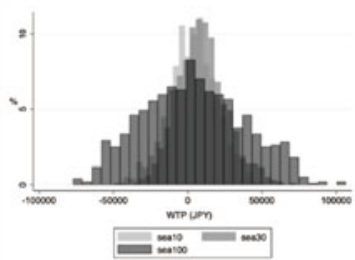

(d) seawall

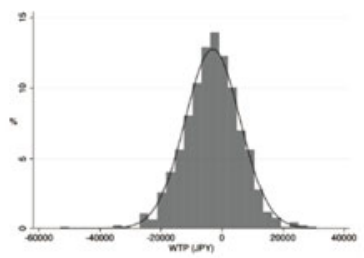

(g) landsc_sea

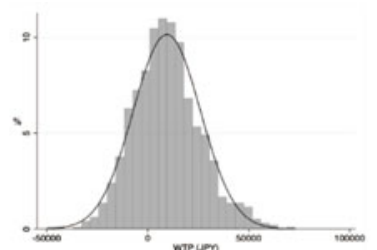

(b) sea30

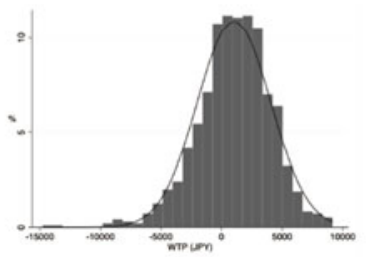

(e) forest

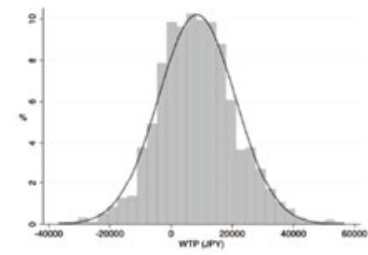

(h) landsc_both

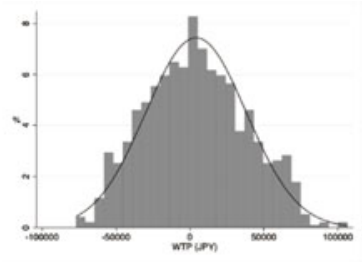

(c) sea 100

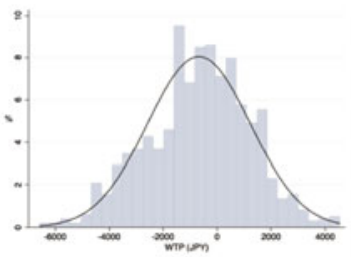

(f) bird

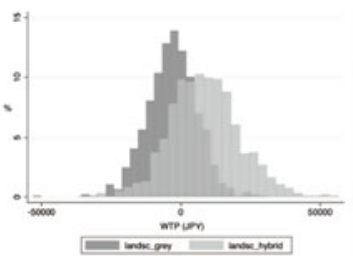

(i) landscape

Fig. 25.8 The distribution of willingness-to-pay (WTP). (a) Seawalls against one-in-10 year probability tsunamis, (b) seawalls against one-in-30 year probability tsunamis, and (c) seawalls against one-in-100 year probability tsunamis. (d) Graph with integrated (a), (b), and (c). WTP for (e) coastal forests, (f) species richness, (g) gray landscape, and (h) hybrid (gray + green) landscape. (i) Graph with integrated (g) and (h) 
forests was estimated to be 957 JPY by the ML, while that of the hybrid landscape was 8245 JPY. Conversely, species richness showed a negative value of -696 JPY with an increasing number of bird species.

\subsection{Discussion and Conclusion}

The analysis presented in this study supports a number of issues, including the tradeoff relationship between ESSs, the monetary values of coastal functions, and the preferences for long-term settings using the stated preference method. However, before discussing our results, we must determine the restrictions of this study. To investigate whether the responders live in areas that are susceptible to tsunamis (TPG), we first specified coordinates using zip codes applied for geocoding. However, the points identified by coordinates do not necessarily indicate their precise location. In particular, zip codes apply to large areas, making it likely that there are higher and lower tsunami risks (Fig. 25.9). Moreover, as 213 respondents hesitated to supply their zip codes, we used their answer to the TPG-related question to group them, as shown in Fig. 25.10. Thus, this process depends on the reliability of their answers. Furthermore, the CL model assumes the same parameters for all respondents, implying that the TPG and the non-TPG each have their own

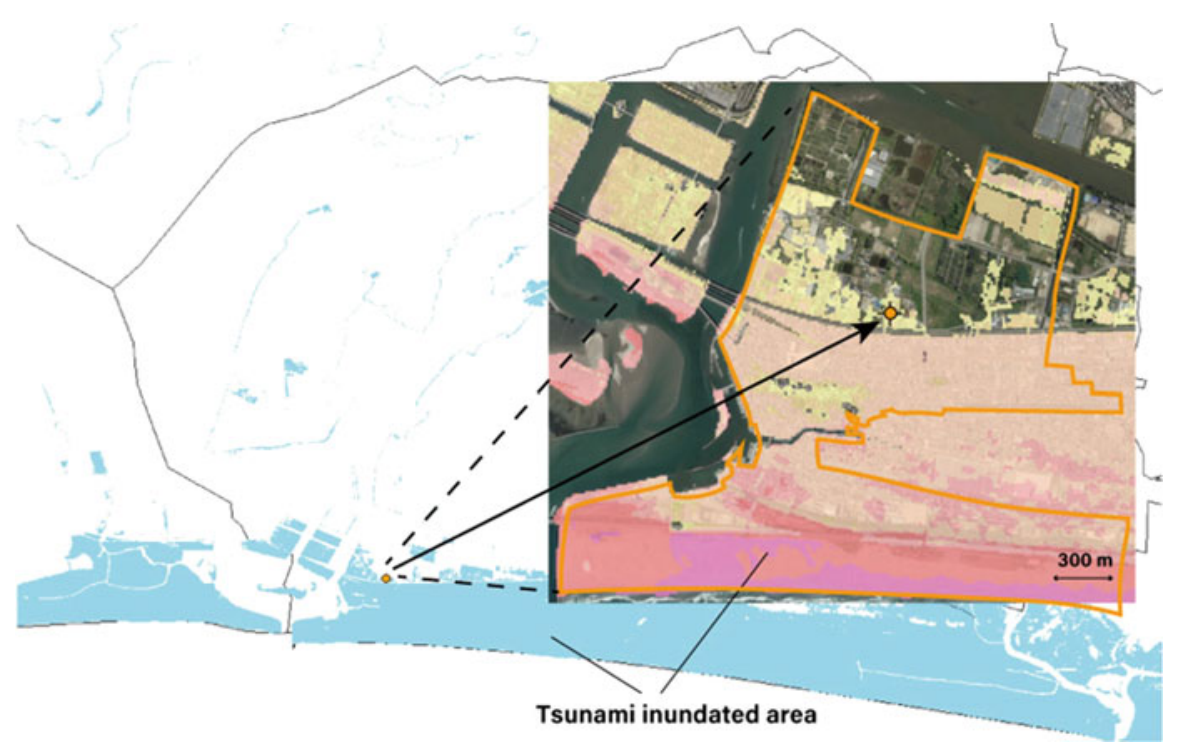

Fig. 25.9 Precision limitations. Note: The polygon represents the typical location identified by the zip codes, and the line depicts a municipal boundary. As the polygon does not identify specific respondents' addresses, it covers both tsunami-prone and lower areas. Hence, there exists a limitation in identifying the respondents in the tsunami-prone areas 


\section{Q33}

Do you live in the area (tsunami-prone area) where it is likely to suffer from tsunamis?

(q33) $=10$ Yes

(q33) $=2 \bigcirc$ No

$(q 33)=30 \mathrm{~N} / \mathrm{A}$

Fig. 25.10 Example question

parameters. Based on the comparisons between the TPG and the non-TPG, the former provided higher WTP values for the DRR function offered by gray than the latter. In particular, the difference in preferences against a short-cycle tsunami was significant (11,233 JPY and 5958 JPY for the TPG and others, respectively). In addition, increasing the scale of coastal forests/100 $\mathrm{m}$ in width had no significance in the TPG. This is probably because of the unstable Eco-DRR effects and the fact that expanding coastal forests may overlap with their residences. Then, more birds were not preferable for the TPG. Despite the economic importance of biodiversity (Martínez et al. 2007; TEEB 2010), for which the bird community is a useful tool for monitoring the onshore environment (Canterbury et al. 2000; Sekercioglu 2006), birds may be associated with negative images of bird droppings, and the drawbacks of certain ESSs, known as ecosystem disservices. Thus, evaluating the economic value of biodiversity remains challenging. Also, only animals in the peak of a food chain should not be spotted, so we need to pay attention to the underestimation of other fauna and flora and to consider the way of evaluating coastal biodiversity in both onshore and offshore environments as well. Regarding landscape, both groups had negative attitudes toward gray-based landscape, especially the TPG (-5439 JPY), whereas TPG had a higher WTP for gray + green landscape (5602 JPY). Considering the understanding of the DRR functions of gray, the negative response toward gray landscape reflects the difficulty of coastal disaster management and installation of hybrid infrastructure. Furthermore, the visual image can affect the responders' decision-making; hence, further development of questionnaire design is necessary.

Meanwhile, the heterogeneities in preferences can be examined using the estimation results from the CL and ML models. Regarding additional seawall height, little attention was paid to low-probability tsunamis, in which a WTP of 2590 JPY was estimated by the ML model. This indicates the importance of considering the individual preferences in comparison to the CL model (11,094 JPY). However, the large gap between CL and ML results in long-cycle tsunamis demonstrates the complexity of predicting people's preferences for future settings (Fig. 25.8d). The coastal forest data suggest that respondents expect coastal forests to function as Eco-DRR, despite the presence of uncertainties. Although the WTP for the 
DRR function of coastal forests is 957 JPY, which is lower than that for gray, ecosystem multifunctionality, encompassing biodiversity, landscape, and recreation, the approximately $60 \%$ of positive answers from respondents must be considered. Overall, a perceived increase in the proportion of coastal disaster reduction in the gray and green infrastructure was shown to attract higher WTP values. As the goods and services resulting from ecosystems are prone to be underestimated (Heal 2000; Beaumont et al. 2008), economic valuation techniques have been developed to capture monetary terms. Moreover, coastal ecosystem functions commensurate with other vegetation (i.e., sand dunes and coral reefs). However, as we have focused on only the onshore environment, only coastal forests were applied in our choice experiments. Chávez et al. (2021) mentioned that coastal green infrastructure encompasses the multi-scale processes of recovery and maintenance, and then it can encourage local people's engagement. Silva et al. (2017) categorized green infrastructure by applying the degree of naturalness ranging from natural to hard engineering and stressed that coastal green infrastructure can be regarded as a series of natural to artificial components. Thus, we need to address how the economic values of coasts in both onshore and offshore environments as a whole can be evaluated. Another thing that needs to be explored is that recreational services were not significant in either model. In order to value coastal recreation and landscape services for cost-benefit analysis, the careful descriptions are required. These economic and ecological constraints have long been a subject of debate. Finally, the ML model demonstrated that the hybrid landscape had over $70 \%$ of positive responses, whereas the gray landscape had approximately $60 \%$ of negative perceptions. Therefore, our study highlighted the recognition of coastal protection offered by gray and green infrastructure, but the question of whether seawalls prevent people from enjoying ocean views remains. Furthermore, even though the hybrid approach is preferable for coastal citizens, identifying the best locations and practice of coastal designs that optimizes gray, green, and hybrid approaches is inevitable (Conger and Chang 2019).

All in all, the results of the TPG and others clarified that the former valued protection function provided by the gray infrastructure. However, the estimated values in the ML model were lower as the scale of seawalls increased for lowprobability tsunamis. In addition, the Eco-DRR of coastal forests was not significant in the TPG, but the ML model showed the necessity of its multifunctionality. Furthermore, hybrid seascapes received positive attention in both groups in both models. These paradoxical views of coastal infrastructure and the heterogeneities of people's preferences may foreshadow the challenges of building a consensus among multiple stakeholders and implementing hybrid approaches. As there is no onesize-fits-all coastal design, it is important to explore long-term resilience planning at regional and local levels from risk reduction socioeconomic and ecological perspectives. In the future, we will examine the risk preferences of people that reside in or will move to hinterlands and higher places where they are less likely to be affected by tsunamis. As their DRR function values may reflect their locations, the hedonic pricing method will be useful. Therefore, the synthesized both stated preference and revealed preference data will help coastal communities provide 
strategic and long-term coastal planning through the interdisciplinary design stage of gray-green combined coastal defense for DRR while simultaneously enhancing the quality of life.

Acknowledgments This research was partially funded by the Environment Research and Technology Development Fund (Project number: 4-1805). We would like to thank the research group from Tokushima University and Takumi Tsuruma and Makoto Nakata from Niigata University. Furthermore, we received extensive support and advice from Nikkei Research Inc. and would also like to thank the respondents of our online surveys.

\section{Appendix}

The questionnaire is provided.

By accounting for the explanations above, please choose the most preferable coastal plans for you. If Plan 1 3 are not preferable, please click "Choose nothing." If the plan has both seawalls and coastal forests, forests are basically located behind seawalls.

\section{Q17T01}

\section{Please choose the most preferable coastal planning for you.} If Plan 1 3 are not preferable, please click "Choose nothing."

You can check the images of situations. Please click here.

You can check the images of situations. Please click here.

\begin{tabular}{|c|c|c|c|c|}
\hline & Plan 1 & Plan 2 & Plan 3 & \\
\hline Additional seawall height & $\begin{array}{l}\text { Prepared for } \\
\text { one-in-30 year } \\
\text { probability tsunami }\end{array}$ & $\begin{array}{l}\text { Prepared for } \\
\text { one-in- } 100 \text { year } \\
\text { probability tsunami }\end{array}$ & No changes & \multirow{6}{*}{ Choose nothing } \\
\hline Coastal forest width $(m)$ & 200 & 0 & 500 & \\
\hline Landscape & Seawall & Seawall & Coastal forest & \\
\hline Recreation & Fishing & Fishing & Walking & \\
\hline Bird species & 3 kinds of birds & 10 kinds of birds & 10 kinds of birds & \\
\hline \multirow[t]{4}{*}{ Annual tax (JPY) } & 30,000 & 3.000 & 3.000 & \\
\hline & Plan 1 & Plan 2 & Plan 3 & \multirow[b]{2}{*}{$\downarrow$} \\
\hline & $\downarrow$ & $\downarrow$ & $\downarrow$ & \\
\hline & 0 & 0 & 0 & 0 \\
\hline
\end{tabular}

Note: The choice experiments were introduced in Q17T01-Q17T08 in the questionnaire. 


\section{References}

Andersen T, Carstensen J, Hernandez-Garcia E, Duarte CM (2009) Ecological thresholds and regime shifts: approaches to identification. Trends Ecol Evolut 24(1):49-57

Bao TQ (2011) Effect of mangrove forest structures on wave attenuation in coastal Vietnam. Oceanologia 53(3):807-818

Barbier EB, Hacker SD, Kennedy C, Koch EW, Stier AC, Silliman BR (2011) The value of estuarine and coastal ecosystem services. Ecol Monogr 81(2):169-193

Bateman IJ, Carson RT, Day B, Hanemann WM, Hanley N, Hett T, Jones-Lee M, Loomes G, Mourato S, Özdemiroglu E, Pearce DW, Sugden R, Swanson J (2002) Economic valuation with stated preference techniques. Edward Elgar

Beaumont NJ, Austen MC, Mangi SC, Townsend M (2008) Economic valuation for the conservation of marine biodiversity. Mar Pollut Bull 56(3):386-396

Bergen SD, Bolton SM, Fridley JL (2001) Design principles for ecological engineering. Ecol Eng 18(2):201-210

Blackwell B (2007) The value of a recreational beach visit: an application to Mooloolaba beach and comparisons with other outdoor recreation sites. Econ Analy Policy 37(1):77-98

Börger T, Beaumont NJ, Pendleton L, Boyle KJ, Cooper P, Fletcher S, Haab T, Hanemann M, Hooper TL, Hussain SS, Portela M, Stithou M, Stockill J, Taylor T, Austen MC (2014) Incorporating ecosystem services in marine planning: the role of valuation. Mar Policy 46:161170

Borsje BW, van Wesenbeeck BK, Dekker F, Paalvast P, Bouma TJ, van Katwijk MM, de Vries MB (2011) How ecological engineering can serve in coastal protection. Ecol Eng 37(2):113-122

Brenner J, Jimenez JA, Sarda R, Garola A (2010) An assessment of the non-market value of the ecosystem services provided by the Catalan coastal zone, Spain. Ocean Coast Manag 53(1):2738

Canterbury GE, Martin TE, Petit DR, Petit LJ, Bradford DF (2000) Bird communities and habitat as ecological indicators of forest condition in regional monitoring. Conserv Biol 14(2):544-558

Chapman MG, Underwood AJ (2011) Evaluation of ecological engineering of "armoured" shorelines to improve their value as habitat. J Exp Mar Biol Ecol 400(1-2):302-313

Chávez V, Lithgow D, Losada M, Silva-Casarin R (2021) Coastal green infrastructure to mitigate coastal squeeze. J Infrastruct Preservat Resilie 2(1):1-12

Cheong SM, Silliman B, Wong PP, Van Wesenbeeck B, Kim CK, Guannel G (2013) Coastal adaptation with ecological engineering. Nat Clim Chang 3(9):787-791

ChoiceMetrics (2018) Ngene 1.2.0 User Manual \& Reference Guide. ChoiceMetrics.http:// www.choice-metrics.com/NgeneManual120.pdf

Conger T, Chang SE (2019) Developing indicators to identify coastal green infrastructure potential: the case of the Salish Sea region. Ocean Coast Manag 175:53-69

Cooper JAG, O'Connor MC, McIvor S (2020) Coastal defences versus coastal ecosystems: a regional appraisal. Mar Policy 111:102332

Costanza R, Pérez-Maqueo O, Martinez ML, Sutton P, Anderson SJ, Mulder K (2008) The value of coastal wetlands for hurricane protection. Ambio 37:241-248

European Commission (2000) Communication from the commission to the council and the European parliament on integrated coastal zone management: a strategy for Europe. https:// ec.europa.eu/environment/iczm/comm2000.htm

Garber-Yonts B, Kerkvliet J, Johnson R (2004) Public values for biodiversity conservation policies in the Oregon Coast Range. For Sci 50(5):589-602

Gedan KB, Kirwan ML, Wolanski E, Barbier EB, Silliman BR (2011) The present and future role of coastal wetland vegetation in protecting shorelines: answering recent challenges to the paradigm. Clim Chang 106(1):7-29

Ghermandi A, Dias N, Paulo A, Portela R, Nalini R, Teelucksingh, SS (2009) Recreational, cultural and aesthetic services from estuarine and coastal ecosystems. FEEM Working Paper No. 121.2009, Available at http://dx.doi.org/10.2139/ssrn.1532803 
Harada K, Imamura F (2005) Effects of coastal forest on tsunami hazard mitigation —a preliminary investigation. In: Satake K (ed) Tsunamis. Springer, Dordrecht, pp 279-292

Heal G (2000) Valuing ecosystem services. Ecosystems:24-30

Helm D, Hepburn C (2012) The economic analysis of biodiversity: an assessment. Oxf Rev Econ Policy 28(1):1-21

Hensher DA, Rose JM, Rose JM, Greene WH (2005) Applied choice analysis: a primer. Cambridge university press

Imamura K, Takano KT, Mori N, Nakashizuka T, Managi S (2016) Attitudes toward disasterprevention risk in Japanese coastal areas: analysis of civil preference. Nat Hazards 82(1):209226

Irtem E, Gedik N, Kabdasli MS, Yasa NE (2009) Coastal forest effects on tsunami run-up heights. Ocean Eng 36(3-4):313-320

Louviere JJ (1988) Conjoint analysis modelling of stated preferences: a review of theory, methods, recent developments and external validity. JTEP 22:93-119

Louviere JJ, Hensher DA, Swait DA (2000) Stated choice methods: analysis and applications. Cambridge University Press

Martínez ML, Intralawan A, Vázquez G, Pérez-Maqueo O, Sutton P, Landgrave R (2007) The coasts of our world: ecological, economic and social importance. Ecol Econ 63(2-3):254-272

McFadden D (1974) Conditional logit analysis of qualitative choice behavior. In: Zarembka P (ed) Frontiers in econometrics. Academic Press, pp 105-142

McGranahan G, Balk D, Anderson B (2007) The rising tide: assessing the risks of climate change and human settlements in low elevation coastal zones. Environ Urban 19(1):17-37

Ministry of Land, Infrastructure, Transport and Tourism (2012) Concepts of Comprehensive Tsunami Countermeasures (original Japanese). http://www.mlit.go.jp/common/000146461.pdf

Morris RL, Konlechner TM, Ghisalberti M, Swearer SE (2018) From grey to green: efficacy of eco-engineering solutions for nature-based coastal defence. Glob Chang Biol 24(5):1827-1842

Onuma A, Tsuge T (2018) Comparing green infrastructure as ecosystem-based disaster risk reduction with gray infrastructure in terms of costs and benefits under uncertainty: a theoretical approach. Int J Disast Risk Reduct 32:22-28

Perkol-Finkel S, Hadary T, Rella A, Shirazi R, Sella I (2018) Seascape architecture-incorporating ecological considerations in design of coastal and marine infrastructure. Ecol Eng 120:645-654

Pioch S, Relini G, Souche JC, Stive MJF, De Monbrison D, Nassif S, Simard F, Allemand D, Saussol P, Spieler R, Kilfoyle K (2018) Enhancing eco-engineering of coastal infrastructure with eco-design: moving from mitigation to integration. Ecol Eng 120:574-584

Prayaga P (2017) Estimating the value of beach recreation for locals in the Great Barrier Reef Marine Park, Australia. Econ Anal Polic 53:9-18

Reeve D, Chadwick A, Fleming C (2018) Coastal engineering: processes, theory and design practice. CRC Press

Schoonees T, Mancheño AG, Scheres B, Bouma TJ, Silva R, Schlurmann T, Schüttrumpf H (2019) Hard structures for coastal protection, towards greener designs. Estuar Coasts 42(7):1709-1729

Sekercioglu CH (2006) Increasing awareness of avian ecological function. Trends Ecol Evol 21(8):464-471

Silva R, Lithgow D, Esteves LS, Martínez ML, Moreno-Casasola P, Martell R, Pereira P, Mendoza E, Campos-Cascaredo A, Grez PW, Osorio AF, Osorio-Cano JD, Rivillas GD (2017) Coastal risk mitigation by green infrastructure in Latin America. Proceed Inst Civil Eng Maritime Eng 170(2):39-54

Spalding MD, Fox HE, Allen GR, Davidson N, Ferdaña ZA, Finlayson MAX, Halpern BS, Jorge MA, Lombana A, Lourie SA, Martin KD, McManus E, Molnar J, Recchia CA, Robertson J (2007) Marine ecoregions of the world: a bioregionalization of coastal and shelf areas. Bioscience 57(7):573-583

Sutton-Grier AE, Wowk K, Bamford H (2015) Future of our coasts: the potential for natural and hybrid infrastructure to enhance the resilience of our coastal communities, economies and ecosystems. Environ Sci Pol 51:137-148 
Takagawa S, Ueta M, Amamo T, Okahisa Y, Kamioki M, Takagi K, Takahashi M, Hayama S, Hirano T, Mikami O, Mori S, Morimoto G, Yamaura Y (2011) JAVIAN database: a specieslevel database of life history, ecology and morphology of bird species in Japan. Bird Res (Orig Japan) 7:R9-R12

Tanaka N (2012) Effectiveness and limitations of coastal forest in large tsunami: conditions of Japanese pine trees on coastal sand dunes in tsunami caused by Great East Japan Earthquake. J Japan Soc Civil Eng Ser B1 (Hydraul Eng) 68(4):II_7-II_15

Task Committee for the Hybrid of Green and Gray Infrastructures (2018) Study on The Hybrid of Green and Grey Infrastructures (original Japanese). https://committees.jsce.or.jp/s_research/ system/files/\%e3\%82\%b0\%e3\%83\%aa\%e3\%83\%bc\%e3\%83\%b3\%e3\%82\%b0\%e3\%83\%ac \%e3\%83\% bc\%e5\%a0\%b1\%e5\%91\%8a\%e6\%9b\%b8\%ef\%bc\%88\%e6\%8f\%90\%e5\%87\%ba $\%$ e7\%89\%88\% ef\%bc\%89.pdf

TEEB (2010) In: Kumar P (ed) The economics of ecosystems and biodiversity ecological and economic foundations. Earthscan, London

Temmerman S, Meire P, Bouma TJ, Herman PM, Ysebaert T, De Vriend HJ (2013) Ecosystembased coastal defence in the face of global change. Nature 504(7478):79-83

Train K (2009) Discrete choice methods with simulation. Cambridge University Press

Open Access This chapter is licensed under the terms of the Creative Commons Attribution 4.0 International License (http://creativecommons.org/licenses/by/4.0/), which permits use, sharing, adaptation, distribution and reproduction in any medium or format, as long as you give appropriate credit to the original author(s) and the source, provide a link to the Creative Commons license and indicate if changes were made.

The images or other third party material in this chapter are included in the chapter's Creative Commons license, unless indicated otherwise in a credit line to the material. If material is not included in the chapter's Creative Commons license and your intended use is not permitted by statutory regulation or exceeds the permitted use, you will need to obtain permission directly from the copyright holder. 